\section{HIV prevalence, AIDS knowledge, and condom use among female sex workers in Santiago, Chile}

\author{
Prevalencia del VIH, conocimientos sobre el SIDA, \\ y uso del condón en trabajadoras sexuales de \\ Santiago, Chile
}

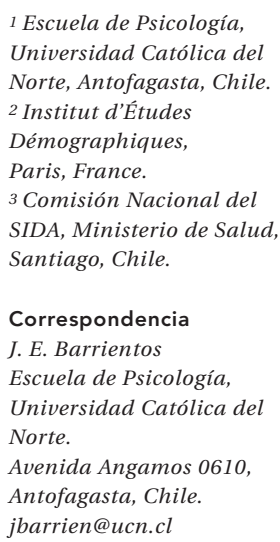

\begin{abstract}
This paper describes HIV seroprevalence, knowledge of HIV transmission, and condom use among female sex workers (FSW) attending five specialized sexually transmitted disease (STD) clinics in Santiago, Chile. A short questionnaire with socio-demographic, AIDS knowledge, and condom-use variables was administered to 626 FSW. HIV seroprevalence was estimated with a blood test sent to the Chilean Public Health Institute. ELISA was used to confirm HIV in suspected cases. HIV prevalence was 0\%. FSW showed adequate overall knowledge of HIV, even better than reported for the Chilean general population on some items. Condom use with clients was high ("always" =93.4\%), although regular use with steady partners was low ("always" = 9.9\%). The zero HIV seroprevalence and consistent condom use with clients confirms the positive impact of intervention strategies for FSW, increasing both correct knowledge of AIDS and condom use with clients and helping decrease these women's HIVI AIDS vulnerability.
\end{abstract}

Sexual Behavior; Condons; HIV; Prevalence
Jaime E. Barrientos 1

Michel Bozon 2

Edith Ortiz ${ }^{3}$

Anabella Arredondo 3

\section{Introduction}

The first AIDS case in Chile was reported in 1984. In 1990, the Chilean government created the National AIDS Commission (or CONASIDA, the Spanish acronym) to respond to the epidemic. CONASIDA has implemented a series of programs including, among others, sentinel surveillance in different centers mainly treating female and transvestite sex workers. Before the creation of CONASIDA, the intervention was centered on sex workers' organization and empowerment. As of December 2005, Chile showed a total of 7,265 AIDS cases, and there were 8,300 persons with HIV in the country 1 . The main form of transmission is unprotected sex, with an increase among women in recent years. There is a relative lack of research on prevalence and quantitative risk behavior, particularly among female sex workers (FSW) 2,3,4. A study by CONASIDA in 1997 showed that HIV prevalence in STD patients who reported participating in the sex trade in the Metropolitan and $5^{\text {th }}$ Regions was only $0.5 \%{ }^{5}$. Nevertheless, Chileans had a very negative perception of sex work, particularly since the beginning of the HIV epidemic. Sex workers, particularly women and transvestites, have thus been stigmatized and subjected to strict police surveillance, unlike their predominantly male clients 6 . However, discrimination against FSW has slowly decreased as a social phenomenon partly due to the AIDS epidemic. Several studies have shown that these 
women use condoms much more frequently than commonly believed 7 . Still, it has not been possible to keep FSW from being perceived as a high-risk group for STDs and HIV; they are often unpopular and socially marginalized, since they are considered vectors of heterosexual HIV transmission 8 . This can produce serious consequences for political decisions related to the epidemic, in some countries leading to the detention or registration of female and transvestite sex workers, demanding their periodic HIV/STD screening 9 .

Sex work is a global phenomenon that appears to increase when the demand for sexual services and a favorable environment coexist. In Chile, $30.5 \%$ of all men (age 18-69) interviewed in COSECON (a nationwide sexual behavior survey), reported having used sexual services at least once in their lifetime, as compared to only $1 \%$ in the previous 12 months 10 . Generally, environments favoring this trade include a high concentration of sexually active people, anonymity, and economic inequalities that foster the existence of a client that can pay and make this an opportunity-benefit situation for FSW 11. However, there are major differences among countries in the way the sex trade is organized and its degree of visibility and institutionalization 12,13. Sex work can be classified as formal (or organized) versus informal. In general, formal sex work occurs in a building or similar structure, and the individuals in charge are the "protectors" and "exploiters" between sex workers and clients. Informal sex workers work in the street or on their own, and their job is different. They sell sex or have sexual intercourse to meet short-term economic needs (for example, to pay off debts), so their work may be even less than permanent. In this context, violence against FSW (particularly street-walkers) has been documented, thus demonstrating their increased HIV vulnerability.

Sex work in Chile, as in many other countries, is illegal and clandestine, drawing police repression against sex workers in the streets 9 . The Chilean legislation is contradictory: sometimes abolitionist, other times seeking to regulate sex work ${ }^{3}$. There is also police control. It is thus difficult to determine the actual magnitude of the phenomenon, although it is regarded as relevant and appears to have increased in recent years. Factors may include economic changes that have made sex a consumer product 13 , and increased female migration to work in the sex trade in northern Chile.

Although there is a strong belief that HIV prevalence is high among FSW, results from North America and Europe show that HIV-infected sex workers often inject drugs 14 , suggest- ing that it is drug use rather than sex work that makes them vulnerable to HIV 15. Studies in Asia, Africa, and Latin America show that HIV prevalence in FSW is extremely diverse (high in some countries and low in others). Therefore, although since the beginning of the AIDS epidemic higher HIV infection rates have been reported in FSW than in other groups, the rates may correspond to certain sex trade subgroups and women living in countries with higher HIV rates 11. In Dakar, Senegal, the infection rate among pregnant women and blood donors is $1.7 \%$, as compared to $10 \%$ in FSW. In Vietnam the rate in pregnant women is $0.12 \%$ and $13 \%$ in FSW in some regions of the country 11. Studies in South Africa have estimated HIV prevalence in FSW at 25\%, the same as in Gambia ${ }^{9}$. Nevertheless, countries like Australia, Bolivia, Madagascar, and Mexico have reported infection rates of $1 \%$ or less in this group.

Meanwhile, there is evidence that FSW are among those with the highest probability of responding positively to HIV/STD prevention programs, for example by increasing condom use with clients. A substantial decrease in HIV prevalence was observed after prevention programs in different countries 16,17. However, there are huge cultural differences that increase the vulnerability of FSW to HIV 18. Some studies suggest that in certain contexts with persistent violence towards women, sex workers do not ask their clients to use condoms because the latter often react violently. Other studies suggest that certain clients prefer to pay more for unprotected sexual intercourse, thus raising the possibility for FSW to increase their earnings.

Evidence suggests that although condom use by FSW is high, it is rather low or irregular with steady partners ("boyfriends" or "lovers") 6. Studies also suggest that it is more difficult for lowincome women to negotiate condom use, thus causing dependence on their partners. Another potentially key factor in condom use relates to the working conditions of FSW. Streetwalking is not the same as working in clubs or brothels, since it is an additional risk factor, with increased violence and police pressure. Other studies suggest that condom use represents a transgression of loyalty and intimacy and can thus cause an imbalance in a steady relationship, because the partner does not want to be treated like a client 19 . Studies further suggest that awareness and knowledge of HIV infection and transmission mechanisms are quite high in these groups 20 . In the context of sex work, the factors most associated with increased vulnerability to HIV are daily number of clients, frequency of sexual intercourse, irregular condom use, STD history and levels, and drug consumption 11. 
Studies so far have generally aimed to answer the following questions: Is sex work regular or occasional? What are the environments for sexual contact? What is the socioeconomic status of women or men involved? Much attention has also been paid to differences in working conditions, sexual behavior, and access to healthcare. Studies focusing on sex trade clients are scarce. Research has also shown the role of STDs as cofactors for HIV infection, and high STD rates have been observed in FSW.

The current study thus aimed to assess HIV prevalence in FSW, their knowledge of AIDS, and condom use in five STD clinics in Santiago, Chile.

\section{Methods}

\section{Sample and procedures}

A stratified random sample was taken from a population of FSW attending five STD centers in Greater Metropolitan Santiago, Chile. The following STD centers located in five health clinics took part in the study: North Metropolitan ( $\mathrm{n}=$ 200), East Metropolitan ( $\mathrm{n}=100)$, Central Metropolitan ( $n=200)$, South Metropolitan $(n=26)$, and Southeast $(n=100)$. The estimated size of the total theoretical sample was selected by considering an expected $0.5 \%$ HIV prevalence rate 5 . The study initially involved two subpopulations. The second subpopulation consisted of women working in the street; however, only the subpopulation attending STD clinics was included in the final study sample. Subjects were treated on a different schedule from the norm in STD clinics, namely after $2 \mathrm{PM}$, since during regular work hours FSW are sleeping or resting after a night's work. They were given pre- and post-HIV test counseling by professionals, and provided written informed consent to participate in the study and test for HIV. Blood samples were taken to the Chilean Public Health Institute (ISP, in the Spanish acronym) for ELISA. Participants answered a questionnaire on socio-demographics, HIV knowledge, and condom use.

A total of 626 subjects answered the questionnaire and were tested for HIV.

Participation criteria were: female sex worker; $\geq 18$ years of age; attending STD clinics; and no previous HIV+ result at the time of the test, according to STD records.

\section{Measurements}

This cross-sectional study used a structured questionnaire with 50 items for face-to-face admin- istration by an interviewer. Socio-demographic variables included age, schooling, marital status, children, time working in sex trade establishments, places of work, current other work, and average monthly income. Other variables were knowledge of HIV and condom use with partners and clients. Detailed definition of the variables is available on request. No previous validation studies of the instrument were performed, so no reliability and validity data are available. Only a pilot test was done to check subjects' understanding of questions.

HIV prevalence was estimated by blood tests. Samples were sent to the ISP. All samples were confirmed by ELISA.

\section{Data analysis}

The analysis was performed with SPSS 11.0 (SPSS Inc., Chicago, USA). For univariate analysis, frequencies and medians of all variables and measures were produced. We examined bivariate associations between individual socio-demographic variables and condom use using the $\chi^{2}$ test with $\mathrm{p}<0.001$. To examine HIV knowledge, findings were compared to those from the first thorough nationwide Chilean survey on sexual behavior, in 1998 (COSECON) 10. COSECON was a milestone in the study of sexuality in Chile, including 5,407 subjects (age 18-69 years). A crosssectional questionnaire with a national probabilistic sample was used, with 2,244 men and 3,163 women. Since COSECON was done in the general population, it was used here only for comparison, given the similarity of many questions. Comparison aimed to show the differences and similarities between the two populations in relation to HIV/AIDS knowledge.

\section{Results}

\section{Socio-demographic profile}

The socio-demographic characteristics of the FSW are shown below. Mean age was 32 years, as shown in Table 1, and more than $60 \%$ were 25-44 years of age. More than half had secondary schooling, and only a minority had no schooling or had reached the university. As for time in the sex trade, the distribution varied among the women. Sex trade locations varied, although local variants such as the so-called "café and legs" do not exist in other countries and are meaningfully related to the other locations.

An important variable for these women is other forms of work. Nearly one-fifth $(n=124)$ reported a second job, while $80 \%$ had the sex 
Table 1

Socio-demographic characteristics of female sex workers from a sample in Chile.

\begin{tabular}{|c|c|c|}
\hline Socio-demographic characteristics & $N=626$ & $\%$ \\
\hline \multicolumn{3}{|l|}{ Age at time of survey (years) } \\
\hline $18-24$ & 157 & 25.1 \\
\hline $25-44$ & 409 & 65.3 \\
\hline$\geq 45$ & 60 & 9.6 \\
\hline \multicolumn{3}{|l|}{ Schooling } \\
\hline$\leq 8$ years (primary) & 197 & 31.5 \\
\hline 8-12 years (junior and high school) & 387 & 61.8 \\
\hline University & 33 & 5.3 \\
\hline None & 5 & 0.8 \\
\hline N.A. & 4 & 0.6 \\
\hline \multicolumn{3}{|l|}{ Time in sex trade at time of survey } \\
\hline$\leq 1$ & 192 & 30.7 \\
\hline $1-5$ & 192 & 30.7 \\
\hline $5-10$ & 116 & 18.5 \\
\hline$\geq 10$ & 126 & 20.1 \\
\hline \multicolumn{3}{|l|}{ Sex trade location } \\
\hline Street & 18 & 2.9 \\
\hline Brothel & 38 & 6.1 \\
\hline Sauna/ massage parlor & 26 & 4.2 \\
\hline "Café and legs" (see text) & 81 & 12.9 \\
\hline Strip club & 202 & 32.3 \\
\hline Nightclub & 222 & 35.4 \\
\hline Other & 39 & 6.2 \\
\hline \multicolumn{3}{|l|}{ Work other than sex trade } \\
\hline Yes & 124 & 19.8 \\
\hline No & 502 & 80.2 \\
\hline \multicolumn{3}{|l|}{ Marital status } \\
\hline Single & 250 & 39.9 \\
\hline Married & 56 & 8.9 \\
\hline Cohabiting & 135 & 21.6 \\
\hline Separated/Marriage annulled/Divorced & 170 & 27.2 \\
\hline Widow & 15 & 2.4 \\
\hline \multicolumn{3}{|l|}{ Current partner status } \\
\hline With partner & 419 & 66.9 \\
\hline Without partner & 207 & 33.1 \\
\hline
\end{tabular}

trade as their only occupation. Finally, as shown in Table 2, $40 \%$ were single $(n=248)$, while more than half had steady partners $(n=144)$.

\section{HIV seroprevalence}

HIV prevalence among the FSW was $0 \%$. This figure is lower than reported elsewhere and even in previous studies in Chile. For example, CONASIDA showed that HIV prevalence in STD patients who reported sex work was $0.5 \%$.

\section{Knowledge on HIV transmission}

Nearly all the FSW reported that vaginal penetration without a condom involves risk of HIV transmission. This result is $10 \%$ higher than the figure in the COSECON survey in 1998, for the general population. Regarding the question on HIV transmission during "French style" sex (a popular local expression for oral sex), more than $80 \%$ responded correctly, while $17.9 \%$ either responded incorrectly that it did not pose any risk or reported that they did not know. This result was $11.6 \%$ higher than the COSECON figures.

Nearly all the FSW reported that there is a risk of AIDS transmission associated with anal penetration without a condom, thus acknowledging the high risk associated with unprotected anal penetration. This result was $9.6 \%$ higher than in the COSECON survey. Some $28.1 \%$ of the interviewees reported risk of AIDS transmission risk associated with masturbation, thus responding incorrectly to this question. Finally, $17.3 \%$ incorrectly reported a risk of AIDS transmission associated with sexual fantasies (Table 3).

\section{Knowledge of HIV prevention}

Approximately $70 \%$ of the subjects correctly acknowledged that using public restrooms does not

Partner status versus marital status.

\begin{tabular}{|c|c|c|c|c|c|c|}
\hline \multirow[t]{3}{*}{ Marital status } & \multicolumn{6}{|c|}{ Current partner } \\
\hline & \multicolumn{2}{|c|}{ With partner } & \multicolumn{2}{|c|}{ Without partner } & \multicolumn{2}{|c|}{ Total } \\
\hline & $\mathbf{n}$ & $\%$ & $\mathbf{n}$ & $\%$ & $\mathbf{n}$ & $\%$ \\
\hline Single & 144 & 34 & 104 & 50 & 248 & 40 \\
\hline Married & 56 & 13 & 2 & 1 & 58 & 9 \\
\hline Cohabiting & 135 & 33 & 0 & 0 & 135 & 21 \\
\hline Marriage annulled/Separated/Divorced/Widow & 84 & 20 & 101 & 49 & 185 & 30 \\
\hline Total & 419 & 100 & 207 & 100 & 626 & 100 \\
\hline
\end{tabular}


Comparison of correct knowledge between female sex workers' study and COSECON (general population) survey.

\begin{tabular}{|c|c|c|}
\hline Question & FSW (\%) & COSECON (\%) \\
\hline \multicolumn{3}{|l|}{ The following involve risk of AIDS transmission } \\
\hline Vaginal penetration without condom & 99.5 & 89.5 \\
\hline "French style" (colloquial expression in Chile for oral sex) & 82.1 & 70.5 \\
\hline Anal penetration without condom & 96.6 & 87. \\
\hline Masturbation & 28.1 & - \\
\hline Sexual fantasy & 17.3 & - \\
\hline \multicolumn{3}{|l|}{ On can prevent AIDS by avoiding } \\
\hline Public restrooms & 68.1 & 60.3 \\
\hline Mosquito bites & 64.5 & 67.1 \\
\hline Sharing bed with AIDS-infected person & 77.5 & - \\
\hline Donating blood & 66.0 & 52.6 \\
\hline Receiving blood & 82.6 & 79.5 \\
\hline Sharing syringes & 98.4 & 94.9 \\
\hline Tattoos & 88.0 & - \\
\hline \multicolumn{3}{|l|}{ One can protect against AIDS by } \\
\hline Choosing a nice-looking partner & 85.3 & 23.2 \\
\hline Washing genitals after each sexual relation & 74.8 & 69.5 \\
\hline Having a regular AIDS test & 32.9 & 39.8 \\
\hline
\end{tabular}

involve AIDS transmission risk. This result was $7.8 \%$ higher than the COSECON figure. $64.5 \%$ of the subjects incorrectly reported that AIDS could be transmitted by mosquito bites. This result was $2.6 \%$ lower than the COSECON figure.

Some $77.5 \%$ of the subjects reported that sharing a bed with a person with AIDS does not transmit AIDS. This question was not included in the COSECON study. $66 \%$ of all women correctly acknowledged that donating blood does not pose any risk of transmission, but $34 \%$ reported that AIDS is not prevented by donating blood. This result was $13.6 \%$ higher than the COSECON figure. $17.4 \%$ of the subjects reported that receiving a blood transfusion does not entail any risk. However, $82.6 \%$ acknowledged risk in receiving blood and therefore responded incorrectly to the question. This result was $3.1 \%$ higher than that in the COSECON survey.

Nearly all the women correctly reported that AIDS is prevented by avoiding sharing syringes or needles and thus acknowledged the risk associated with this practice. This result was $3.5 \%$ higher than in the COSECON survey. Finally, $88 \%$ reported that AIDS is prevented by avoiding being tattooed, whereas at least $12 \%$ reported lack of information or responded incorrectly.

\section{Knowledge of HIV versus AIDS protection}

Some $85.3 \%$ of the interviewees reported that choosing a nice-looking sex partner does not protect against AIDS. Only $14.7 \%$ of the interviewees thought that choosing a nice-looking sex partner protects against AIDS. This result contrasted remarkably with the figure for the national population, in which only $23.2 \%$ answered correctly. The difference was thus $62.1 \%$ between the two studies.

Nearly three-fourths of the FSW reported that washing after sexual intercourse does not protect against AIDS. These results were 5.3\% higher than for the national population. Finally, $32.9 \%$ of FSW reported incorrectly that having a regular AIDS test protects against the disease. This result was $6.9 \%$ lower than for the national population.

\section{Condom use}

Most subjects reported always using condoms with clients. Only $6.6 \%$ reported occasional or no use (Table 4).

Consistent condom use with clients was quite high for each age group, with the highest in the 18-24-year group, although this difference was not statistically significant. The figure for little or no condom use was higher for the oldest group. 
Table 4

Condom use by female sex workers with clients.

\begin{tabular}{lcc}
\hline Condom use with clients & $\mathbf{n}$ & $\%$ \\
\hline Always & 522 & 93.4 \\
Sometimes & 32 & 5.7 \\
Never & 5 & 0.9 \\
Total & 559 & 100.0 \\
\hline
\end{tabular}

As for schooling, higher condom use was observed in women with more education, $\chi^{2}(9)=$ 28.718. Regarding partner status, the proportion of rare or irregular condom use with clients was observed in married and cohabiting women, followed by single women with partners, $\chi^{2}(18)=$ 70.945 .

If only women with partners are analyzed, more than three-fourths $(77.7 \%)$ reported never using condoms during intercourse with their partners, whereas only $9.9 \%$ reported consistent condom use with partners (Table 5).

Even though regular condom use partners (whatever their status) was low, the figure was higher for single women with partners, followed by separated or divorced women and widows. Compared to other forms of partner status, married or cohabiting women reported little or no condom use, $\chi^{2}(24)=1,272.678$. Finally, no statistically significant differences were observed in condom use with partners according to age, schooling, or having other work besides the sex trade.

\section{Conclusions}

The results showed that HIV prevalence in this sample of FSW in Chile was zero, thus lower than reported in other countries for the same kind of

Table 5

Condom use by female sex workers with steady partners.

\begin{tabular}{lcc}
\hline Condom use with steady partner & $\mathbf{n}$ & $\%$ \\
\hline Always & 41 & 9.9 \\
Sometimes & 51 & 12.4 \\
Never & 321 & 77.7 \\
Total & 413 & 100.0 \\
\hline
\end{tabular}

population. This finding was remarkable since it showed that prevention work by NGOs and the government with FSW has been successful, particularly peer education, which has facilitated the use of tools for FSW to negotiate condom use with clients. These women have been exposed to several types of interventions that have increased their HIV risk management skills, implying that the sample may not represent the entire sex trade population in Santiago. Therefore, future research should include the population that did not participate in the current study (especially women working on the streets) due to the police repression against them at the time.

Another interesting and unique finding was the large number of women involved in undercover sex trade in places known as "cafés and legs". "Cafés and legs" are quite original and have expanded in Chile, a country with a limited tradition of drinking fresh-roasted coffee. Apart from their regular jobs, some "cafés and legs" waitresses are also engaged in undercover sexual trade. It is thus necessary to strengthen prevention in this context.

At least $20 \%$ of the women interviewed had jobs outside the sex trade. Analyzing this result may allow approaching matters related to other sources of income, female sex work safety, and conditions that increase the need to engage in the sex trade. Nevertheless, the study did not show any important differences between women working only in the sex trade and those with other kinds of work.

Another remarkable finding was women's knowledge about HIV: they knew the risks of unprotected sexual intercourse. Preventive intervention may have had a meaningful impact on this population, and it may contribute to the improvement of both knowledge and the skills to negotiate condom use with clients. Nevertheless, Chile has no legislation on this issue, and social and sexual violence as well as police repression toward these women persist, especially for women working in the streets. It is thus necessary to continue working and particularly legislating for the protection of these women's rights. This finding is relevant in light of the characteristics of the HIV epidemic in Chile because, for example, housewives are the part of the population most affected by HIV. Thus, these findings could be used to implement specific interventions among this group, that is, actions including successful lessons learned from other groups of women. These actions should be implemented through STD centers in order to guarantee their continuity.

Finally, it is important to note that although $39.9 \%$ of the women were single and only $8.9 \%$ 
married, many reported having steady partners (66.9\%). This issue is crucial because, as reported in other studies, although regular condom use with "clients" was high, a greater percentage reported irregular condom use with stable partners, particularly among married women, because they are quite familiar with the risks associated with these practices. It is not possible to state, however, that the number of women using condoms with clients has increased, because no previous studies exist for comparison. This fact has important implications for STD and HIV prevention policies, since many of these women, being in a partnership context, could believe that they are protected from HIV infection and could thus be avoiding condom use. It is therefore essential to reinforce prevention strategies among FSW with steady relationships.

\section{Resumen}

Este artículo examina la prevalencia del VIH, los conocimientos respecto a su infección y, además, describe el uso del condón en mujeres que ejercen el comercio sexual en Santiago de Chile y que son atendidas en cinco centros especializados de enfermedades de transmisión sexual. Se aplicó una encuesta que indagaba sobre las características sociodemográficas, el conocimiento sobre el VIH/SIDA y el uso del condón a 626 mujeres. La prevalencia del VIH fue evaluada mediante un examen de ELISA. La prevalencia del VIH fue 0. El conocimiento del VIH fue bueno e, incluso, mejor que en población general, en algunos indicadores. El uso del condón con los clientes fue alto, aunque su uso regular con las parejas estables fue bajo. La prevalencia cero del VIH y el uso consistente de condones con los clientes confirma el impacto positivo que han tenido las estrategias de intervención implementadas para estos grupos, incrementando el conocimiento adecuado sobre el SIDA y el uso del condón con los clientes, contribuyendo a la disminución de la vulnerabilidad de estas mujeres hacia el

Conducta Sexual; Condones; VIH; Prevalencia
One limitation of this study was the exclusion of other populations treated at this type of clinic, for example female or transvestite streetwalkers. Nor does the study deal with prevalence in other areas of the country where prevention is often less systematic, particularly in a country like Chile with enormous geographic differences. Besides, caution must be taken with the question about "condom use", since the period of time in which these populations used condoms was not specified (for example, in the previous year, previous month, or during last sexual intercourse). Caution is also advised when comparing studies using totally different methods and sampling strategies, like the COSECON survey and the current study. Finally, future studies should include social and psychosocial dimensions not dealt with in this study, such as the reasons for female sex work and client characteristics.

\section{Contributors}

A. Arrendondo and E. Ortiz planned the study, data collection, and database. J. E. Barrientos worked in the data analysis and literature review. M. Bozon participated in the discussion of findings. Finally, J. E. Barrientos and M. Bozon participated in the discussion of the findings.

\section{Acknowledgements}

The authors with to thank CONASIDA for its collaboration. 


\section{References}

1. Departamento de Estadísticas e Información de Salud, Ministerio de Salud. Bases de datos ENO, 1990-2003. http://www.sernam.cl/basemujer/ index.htm (accessed on 05/Feb/2004).

2. Fuentes E. Estudio acerca de las mujeres que ejercen la prostitución callejera. Santiago: Instituto de la Mujer; 1993. (Documentos de Trabajo del Área de Salud).

3. Montecino S, Matus C, Donoso C. Estudio: prostitución juvenil urbana. Santiago: Instituto Nacional de la Juventud; 1999.

4. Vidal P, Cerva D, Cortés M, Talloni N. Investigación diagnostica: prostitución juvenil femenina en Santiago. Santiago: Instituto de la Mujer; 1997.

5. Comisión Nacional del SIDA, Ministerio de Salud. Informe sobre seroprevalencia en población de trabajadoras sexuales. Santiago: Ministerio de Salud; 1998.

6. Jackson LA, Sowinski B, Bennett C, Ryan D. Female sex trade workers, condoms, and the public-private divide. J Psychol Human Sex 2005; 17:83-105.

7. Vanwesenbeeck I. Prostitutes' well-being and risk. Amsterdam: VU University Press; 1994.

8. Elmore-Meegan M, Conroy R, Agala B. Sex workers in Kenya, numbers of clients and associated risks: an exploratory survey. Reprod Health Matters 2004; 12:50-7.

9. Maia J, Malala J. Condom use, power and HIV/ AIDS risks: sex-workers bargain for survival in Hillbrow/Joubert Park/Berea, Johannesburg. Soc Sci Med 2001; 53:99-121.

10. Comisión Nacional del SIDA, Ministerio de Salud/ Agence Nationale de Recherches sur le SIDA. Encuesta de comportamiento sexual. Primeros análisis. Santiago: Ministerio de Salud; 2000.
11. Joint United Nations Programme on HIV/AIDS. Sex work and HIV/AIDS. Geneva: Joint United Nations Programme on HIV/AIDS; 2002. (UNAIDS Technical Update).

12. Lastra T. Las "otras" mujeres. Santiago: Colecciones APRODEM; 1997.

13. Rajevic P. El libro abierto del amor y el sexo en Chile. Santiago: Editorial Planeta Chile; 2000.

14. Spina M, Mancuso S, Sinicco A, Vaccher E, Traina C, Di Fabrizio N, et al. Increase of HIV seroprevalence among professional prostitutes in Italy. AIDS 1997; 11:545-6.

15. Vanwesenbeeck I. Another decade of social scientific work on sex work: a review of research 19902000. Annu Rev Sex Res 2001; 12:242-89.

16. Ghys P, Diallo M, Ettiegne-Traore K, Tawil O, Carael M, Traore M, et al. Increase in condom use and decline in HIV and sexually transmitted diseases among female sex workers in Abidjan, Cote d'Ivoire, 1991-1998. AIDS 2002; 16:251-8.

17. Alary M, Mukenge-Tshibaka L, Bernier F, Geraldo $\mathrm{N}$, Lowndes C, Meda H, et al. Decline in the prevalence of HIV and sexually transmitted diseases among female sex workers in Cotonou, Benin, 1993 -1999. AIDS 2002; 16:463-70.

18. Wechsberg W, Luseno W, Lam W. Violence against substance-abusing South African sex workers: intersection with culture and HIV risk. AIDS Care 2005; 17 Suppl 1:S55-64.

19. Varga C. The condom conundrum: Barriers to condom use among commercial sex workers in Durban, South Africa. Afr J Reprod Health 1997; 1:7488.

20. Abdool-Karim Q, Abdodool-Karim SS, Nkomokazi J. Sexual behavior and knowledge of AIDS among urban black mothers. S Afr Med J 1991; 80:340-3.

Submitted on 17/Apr/2006

Final version resubmitted on 25/Sep/2006

Approved on 24/Jan/2007 